\title{
Policiais Militares do Estado do RS: Relação entre Satisfação no Trabalho e Estresse Ocupacional
}

Damiana Machado de Almeida Doutoranda em Administração pelo PPGA-UFSM Universidade Federal de Santa Maria/ Doutoranda http://lattes.cnpq.br/5642167686175158 https://orcid.org/0000-0001-6433-9212 adm.damiana@gmail.com

Luis Felipe Dias Lopes Doutor em Engenharia de Produção/UFSC Universidade Federal de Santa Maria/ Professor Titular do Departamento de Ciências http://lattes.cnpq.br/1074372911061770 https://orcid.org/0000-0002-2438-0226 Iflopes67@yahoo.com.br

Vânia Medianeira Flores Costa Doutora em Administração/UFBA Universidade Federal de Santa Maria/ Professora Associada do Departamento de Ciências Administrativas http://lattes.cnpq.br/0180563343119839 https://orcid.org/0000-0002-6099-820X

vania.costa@ufsm.br

Rita de Cássia Trindade dos Santos Mestranda em Administração/PPGA-UFSM Universidade Federal de Santa Maria/ Mestranda http://lattes.cnpq.br/0203083920075858 https://orcid.org/0000-0001-8970-9494 rita.santos0606@gmail.com

Resumo: Objetiva-se analisar as relações entre satisfação no trabalho e estresse ocupacional na perspectiva dos policiais militares do estado do Rio Grande do Sul. Realizou-se uma pesquisa descritiva, do tipo survey, com abordagem quantitativa. Participaram 519 policiais militares de 97 cidades do Rio Grande do Sul. Aplicou-se a Escala de Satisfação no Trabalho (SIQUEIRA, 2008) e a Escala de Estresse no Trabalho (PASCHOAL e TAMAYO, 2004). Identificou-se correlação negativa e estatisticamente significante entre o estresse ocupacional e a satisfação no trabalho e suas dimensões, classificando tais relações como moderadas e negativas, isto demonstra que quanto maior o estresse ocupacional, menor a satisfação no trabalho, e vice-versa. Houve associação entre a satisfação baixa e o estresse alto, e da mesma forma, houve associação entre satisfação média e estresse médio. Assim, demonstrou-se relação entre a satisfação no trabalho e o estresse ocupacional, influenciando-se inversamente.

Palavras-chave: Satisfação no Trabalho, Estresse Ocupacional, Policiais Militares, Trabalho

\begin{abstract}
The objective is to analyze the connection between job satisfaction and occupational stress from the perspective of the police officers of the state of Rio Grande do Sul. It was conducted quantitative descriptive research, using the survey method. Five hundred and nineteen police officers from 97 cities in Rio Grande do Sul participated in the study. Two scales were used: the Satisfaction at Work Scale at Work (SIQUEIRA, 2008) and the Job Stress Scale (PASCHOAL and TAMAYO, 2004). It was identified statistically significant connection between job stress and job satisfaction and its dimensions, classifying such relationship as moderate and negative. This shows that the higher the occupational stress, the lower the job satisfaction and vice versa. There was an association between low satisfaction and high level of stress. There was also an association between average satisfaction and medium leve stress. Thus, it was demonstrated the relationship between job satisfaction and occupational stress, one aspect influencing the other.
\end{abstract}

Keywords: Job Satisfaction, Occupationa stress, police, Work
Resumen: Se pretende analizar las relaciones entre satisfacción en el trabajo y estrés ocupacional en la perspectiva de los policías militares del estado de Rio Grande do Sul. Se realizó una investigación descriptiva, del tipo survey, con abordaje cuantitativo. Participaron 519 policías militares de 97 ciudades de Rio Grande do Sul. Se aplicó la Escala de Satisfacción en el Trabajo (SIQUEIRA, 2008) y la Escala de estrés en el trabajo (PASCHOAL y TAMAYO, 2004). Se identificó correlación negativa y estadísticamente significativa entre el estrés ocupacional y la satisfacción en el trabajo y sus dimensiones, clasificando tales relaciones como moderadas y negativas, esto demuestra que cuanto mayor sea el estrés ocupacional, menor es la satisfacción en el trabajo, y viceversa. Hubo asociación entre la satisfacción baja y el estrés alto, y de la misma forma, hubo asociación entre satisfacción media y estrés medio. Así, se demostró relación entre la satisfacción en el trabajo y el estrés ocupacional, influenciándose inversamente.

Palabras clave: Satisfacción en el Trabajo, Estrés Ocupacional, Policías Militares, Trabajo

Texto completo em português: http://www.apgs.ufv.br Full text in Portuguese: http://www.apgs.ufv.br

\section{INTRODUÇÃO}

A atividade profissional sofre influência de vários fatores, como físicos, psíquicos, familiares, sociais, os quais acarretam consequências. As tecnologias, o ritmo de trabalho, a pressão por resultados, as relações entre a equipe, a afetividade ou a falta dela e a estrutura de trabalho são alguns dos aspectos, que atingem diretamente as pessoas.

De acordo com o Ministério da Saúde e Organização PanAmericana da Saúde no Brasil (BRASIL, 2001), o estresse toma 
espaço nesse cenário e exige cada vez mais pesquisas para que se conheça, com mais profundidade, o tema e se possam traçar estratégias efetivas de prevenção. Complementando essa tendência, Paschoal e Tamayo (2004) afirmam que um dos principais motivos pelo aumento no número de pesquisas sobre estresse é o seu impacto negativo sobre a saúde e o bem-estar do trabalhador e, consequentemente, sobre a produtividade e o funcionamento da organização.

Dentre os profissionais, que estão mais propensos ao estresse no trabalho, em função da pressão e dos riscos das atividades diárias, estão os policiais militares (COSTA et al., 2007). As principais responsabilidades assumidas por eles no Estado do Rio Grande do Sul (RS) são: executar a polícia ostensiva, a fim de assegurar o cumprimento da lei e a manutenção da ordem pública; atuar em casos de perturbação da ordem pública e no gerenciamento técnico de situações de alto risco; realizar os serviços de busca e salvamento aéreo, aquático e terrestre, e executar a guarda externa dos estabelecimentos prisionais do Estado (BRIGADA MILITAR, 2015).

Apesar da importância do tema estresse ocupacional, em policiais militares, tanto para o indivíduo, para o Governo Estadual e para a sociedade em geral, é comprovado que essa classe profissional não vem sendo estudada em profundidade. A profissão é uma das que mais sofre estresse, visto que trabalha sob forte tensão, em situações que colocam em risco a sua própria vida (COSTA et al., 2007; OLIVEIRA e BARDAGI, 2010).

O campo de estudo que trata da saúde do trabalhador, para ser coerente com a realidade atual, não pode se omitir em relação às categorias que atuam na Segurança Pública, visto que esse é um dos segmentos, que apresenta maior vulnerabilidade em relação ao trabalho (SOUZA e MINAYO, 2005).

Vasconcelos (2011) ratifica que, como os policiais são expostos a situações de estresse, faz-se necessário a realização de pesquisas, a fim de que os gestores possam conhecer e compreender as respostas do seu efetivo em relação ao estresse, a traumas e ao abuso de substâncias. Só assim será possível intervir, implementando estratégias e os tratamentos necessários para auxiliar estes profissionais a sobreviverem ao rigor do contexto ocupacional.

Outra temática que merece atenção é a satisfação no trabalho. Para Siqueira (2008), refere-se ao vínculo afetivo do indivíduo com o seu labor. Há evidência de que a satisfação no trabalho está ligada a fatores socio-organizacionais, como valores, percepções de justiça, de suporte e de reciprocidade, que se estabelecem a partir das trocas entre indivíduo, colegas e organização. Sendo assim, a satisfação no trabalho está diretamente relacionada e dependente das políticas e práticas gerenciais da organização.

Ademais, no que se refere à satisfação no trabalho, saber o que satisfaz o colaborador é importante para se definirem os procedimentos a serem adotados, buscando-se aprimorar seu desempenho, por conseguinte, o da instituição. Para Oliveira (2012), cabe salientar que a satisfação no trabalho é uma das variáveis do comportamento organizacional mais estudada por duas razões: por ser um dos mais importantes resultados no trabalho e por ter sido, implícita ou explicitamente, associada ao desempenho.

Por esse motivo, justifica-se a relevância social e acadêmica do presente estudo, tendo em vista a qualificação da gestão pública, no que tange ao atendimento das necessidades dos trabalhadores desse setor, em especial, o policial militar e as implicações de seu contexto de trabalho. Além disso, apropriar-se desse tipo de informação pode auxiliar os gestores públicos na elaboração de práticas e políticas de gestão adequadas à realidade do quadro de pessoal, tanto para o desenvolvimento daqueles, que já exercem as atividades cotidianas de trabalho quanto para a capacitação de novos profissionais.

Em face dessas considerações e para fins dessa pesquisa formulou-se o seguinte problema de pesquisa: Existe relação entre satisfação no trabalho e estresse ocupacional nos policiais militares do Estado do Rio Grande do Sul? Do qual emerge o seguinte objetivo geral de pesquisa: analisar as relações entre satisfação no trabalho e estresse ocupacional na perspectiva dos policiais militares do Estado do Rio Grande do Sul, e como objetivos específicos: (1) caracterizar o perfil dos pesquisados; e (2) associar o nível de satisfação no trabalho com o nível de estresse ocupacional dos policiais militares pesquisados.

O presente artigo é apresentado em cinco partes. A primeira delas é a introdução, que contextualiza a pesquisa e apresenta os objetivos. Na sequência, uma breve revisão de literatura acerca das temáticas, satisfação no trabalho e estresse ocupacional. A terceira parte descreve o método utilizado para atingir os objetivos. Posteriormente, são discutidos os resultados encontrados e, por fim, são apresentadas as considerações finais sobre a pesquisa, enfatizando a relevância dos seus achados, assim como suas limitações.

\section{SATISFAÇÃO NO TRABALHO}

Desde as primeiras décadas do século $X X$, o tema satisfação no trabalho vem despertando o interesse de pesquisadores da área do comportamento organizacional. Isso, em função da necessidade em se compreender os sentimentos envolvidos entre os colaboradores e a relação entre a satisfação e o processo motivacional. Nesse período, os pesquisadores defendiam que o tema era um componente da motivação, responsável por determinados comportamentos importantes para a empresa, tais como: aumento de desempenho, aumento da produtividade, redução de faltas, índices de acidentes e de rotatividade. Sendo assim, a satisfação era considerada a causa de determinado comportamento no trabalho, influenciando diretamente no sucesso ou fracasso da organização (SIQUEIRA, 2008; FIGUEIREDO, 2012).

Nos anos de 1970 e 1980, Figueiredo (2012) explica que as pesquisas relacionadas ao tema passaram a focar na identificação das dimensões que constituem a motivação, como salário, promoção, supervisão, método de trabalho, assim como na forma com que esses fatores se relacionam. As características dos 
colaboradores também foram consideradas, bem como o contexto no qual estava sendo desenvolvido o estudo.

Segundo Siqueira e Gomide Júnior (2004), outra concepção de estudo se refere à relação da satisfação no trabalho com pressupostos humanistas e sociais, que buscam, das empresas, uma maior responsabilidade social. Para os pesquisadores, mensurar os níveis de satisfação poderia ser uma forma de monitorar o quanto as empresas conseguem promover a saúde e o bem-estar dos colaboradores. Essa concepção parte do princípio de que os sentimentos, oriundos do contexto, são extensivos a vida pessoal, familiar e social dos indivíduos, influenciando os níveis de bem-estar, saúde física e mental.

Martinez e Paraguay (2003) comentam que houve uma evolução na concepção do tema. Inicialmente, considerava-se que o trabalhador reagia mecanicamente a fatores externos e que a satisfação estava ligada diretamente ao salário. Depois, surgiu a concepção que considera a interação entre aspectos psicossociais e a subjetividade, produzindo diferentes níveis de satisfação e influenciando, diretamente, a qualidade de vida, o comportamento e a saúde do indivíduo, além de apresentar consequências para a organização.

Gondim e Siqueira (2004) salientam que, nos anos de 1990, as pesquisas focaram nas emoções oriundas do ambiente de trabalho, como afetos, ânimo e emoções, reduzindo-se a visão abrangente das pesquisas anteriores. Os achados foram importantes, pois fundamentaram a compreensão a respeito de estresse, burnout e saúde dos trabalhadores. Ferreira e Siqueira (2005) comentam que a definição de satisfação no trabalho apresenta várias abordagens. Para Spector (2012), satisfação é uma variável de atitude, que reflete como a pessoa se sente com relação ao trabalho, considerando-se vários fatores envolvidos em sua rotina, como colegas, salário, natureza do trabalho e supervisor.

De acordo com Siqueira e Gomide Júnior (2004), no século XXI, o conceito de satisfação está vinculado à afetividade no ambiente ocupacional, isto é, um vínculo afetivo do indivíduo com o trabalho. Siqueira (2008) complementa que a satisfação no trabalho se refere à compreensão do quanto o colaborador vivencia experiências prazerosas na organização. Já Caldas et al. (2013) consideram tais experiências como um antecedente de desempenho profissional, usadas como indicador de saúde.

Outro conceito de satisfação no trabalho é apresentado por Rothmann e Cooper (2009), o qual consiste no estado emocional prazeroso, positivo, resultante do julgamento do trabalho ou da experiência de alguém. Os principais fatores, que influenciam a satisfação, estão relacionados à organização, aos grupos e às pessoas. Figueiredo (2012) reforça que, alguns autores, consideram o conceito de difícil compreensão, em função da sua subjetividade, pois reflete experiências e percepções do colaborador, representando aspectos de sua vida individual, influenciando não só as condições de trabalho como a situação econômica e social, repercutindo na sua vida laboral.

Outro fator relevante, que é destacado por Siqueira (2008), se refere às pesquisas realizadas que, até então, revelavam características pessoais dos trabalhadores e do ambiente físico, assim como a estrutura da organização, porém pouco contribuiu para explicar as variações nos níveis de satisfação. Em contrapartida, outros estudos brasileiros, segundo esse autor, apontam grande influência dos fatores do contexto socioorganizacional, como valores, percepção de justiça, suporte e reciprocidade nas relações de trocas sociais e econômicas entre os colaboradores e a empresa. Percebe-se que a satisfação no trabalho é sensível às políticas e às práticas gerenciais, principalmente, aquelas que envolvem a distribuição de retornos, demonstrando o quanto a empresa está comprometida com a equipe, com o bem-estar e o quanto esta equipe estaria disposta a retribuir seus esforços. Assim, parece correto afirmar que, ao conhecer as causas e as consequências da satisfação no trabalho, é possível, ao gestor, conduzir esses fatores de forma a contribuir com resultados cada vez mais benéficos à empresa, interferindo, inclusive, na eficiência dos seus colaboradores.

Visando mensurar a satisfação no trabalho, pesquisadores elaboraram e validaram vários instrumentos ao longo do tempo. Martins e Santos (2006) mencionam que o instrumento de medida de satisfação no trabalho mais antigo é o de Brayfield e Rothe, de 1951, e que pode ter sido o mais utilizado e o que tenha maior impacto na literatura da área. Outro instrumento importante, segundo Spector (2012), é o Índice Descritivo do Trabalho (IDT), de Smith, Kendall e Hullin, de 1969, sendo também utilizado em muitas pesquisas. Esse instrumento avalia as cinco dimensões da satisfação no trabalho que são: trabalho, salário, oportunidades de promoção, supervisão e colegas de trabalho; sendo constituído por 72 itens com possibilidade de três respostas: sim, não e talvez.

Valle (2007) aborda o instrumento Job Diagnostic Survey (JDS), elaborado por Hackman e Oldham, em 1976, o qual foi considerado, pela literatura, como um dos mais abrangentes instrumentos para mensurar o nível de satisfação no trabalho. $O$ instrumento identifica cinco fatores, denominados de características essenciais ao cargo, divididas em: variedade de habilidades, identidade da tarefa, significância da tarefa, autonomia e feedback. Possui 83 questões e utiliza escala tipo Likert de sete pontos.

Segundo Neves (2012), um dos primeiros instrumentos elaborados e validados no contexto nacional foi o de Siqueira, em 1978, chamado Questionário de Medida de Satisfação no Trabalho (QMST). Após análise fatorial, o instrumento permaneceu com 80 itens e sete fatores, sendo estes: satisfação geral, desgaste físico e psicológico, status da função, localização da empresa, benefícios compensadores, reconhecimento e desenvolvimento pessoal.

Mais recentemente, Martins e Santos (2006) revalidaram a Escala de Satisfação no Trabalho, elaborada, anteriormente, por Martins, em 1984. Após readaptá-la, semanticamente, e revalidá-la, a escala ficou composta por 45 itens reunidos em seis constructos, que são: satisfação com o suporte organizacional, insatisfação com a falta de suporte psicossocial, satisfação com a utilidade social da organização e do trabalho, satisfação com relacionamento afetivo no trabalho, satisfação com o reconhecimento profissional e insatisfação com a sobrecarga de trabalho. 
Já Siqueira (2008) desenvolveu a Escala de Satisfação no Trabalho (EST), a partir de uma visão multidimensional, em que a expressão "satisfação no trabalho" se refere à totalização do quanto o indivíduo, que trabalha, vivencia experiências prazerosas no contexto das organizações. Desse modo, cada uma das cinco dimensões de satisfação no trabalho compreende uma origem de tais experiências prazerosas sendo, portanto, utilizadas as expressões: "satisfação com..." (O salário, os colegas, a chefia, as promoções e o próprio trabalho). Mensurar a satisfação no trabalho significa avaliar o quanto investimentos, realizados por parte da empresa, como salários e promoção, o quanto a convivência com os colegas e as chefias e o quanto a realização das tarefas propiciam, ao colaborador, sentimentos positivos.

Siqueira (2008) alerta que é importante, que o instrumento para medir satisfação permita avaliar não um amplo leque de dimensões do trabalho, mas os aspectos que a teoria aponta como dimensões do conceito de satisfação. Deve ser de fácil aplicação, permitindo aos trabalhadores compreender o que se solicita, escolhendo suas respostas com tranquilidade. $O$ instrumento também permite a transformação dos dados em resultados, que possam ser interpretados tanto no âmbito da pesquisa científica quanto na prática gerencial.

No contexto do presente estudo, adotou-se a Escala de Satisfação no Trabalho (EST) de Siqueira (2008), por já ter sido validada no Brasil e por não ser instrumento extenso, o que poderia prejudicar o tempo de concentração, para determinar a resposta que melhor representa a situação, em cada questão, da respectiva dimensão.

A partir do exposto, percebe-se que a satisfação no trabalho depende do quanto as várias dimensões estão sendo atendidas. Assim, deve-se monitorar, frequentemente, o índice dessas dimensões, pois impacta diretamente nos resultados esperados da equipe. A falta da satisfação acarreta aspectos negativos, como absenteísmo, rotatividade de pessoal, além de baixo desempenho do colaborador (ROTHMANN e COOPER, 2009).

Apresentadas as principais considerações a respeito da temática satisfação no trabalho, passa-se para uma breve revisão teórica sobre estresse ocupacional.

\section{ESTRESSE OCUPACIONAL}

A temática Estresse Ocupacional se desenvolveu a partir da década de 1970, no intuito de analisar as condições de trabalho, bem como suas consequências para a saúde e o desenvolvimento do indivíduo (HURRELL Jr. e SAUTER, 2011).

Paschoal e Tamayo (2004, p. 46) mencionam que o estresse ocupacional é definido "como um processo em que o indivíduo percebe demandas do trabalho como estressores, os quais, ao exceder sua habilidade de enfrentamento, provocam no sujeito reações negativas". Ainda, segundo os autores, na organização para determinado fator ser considerado estressor, este deve ser reconhecido como tal pelo colaborador. Os estressores ocupacionais têm natureza física ou natureza psicossocial, sendo este último o mais estudado e relacionado a fatores intrínsecos ao trabalho, relacionamento interpessoal, assim como a fatores ligados à carreira.

Xavier, Rios e França-Botelho (2013) alertam que a associação entre sensação de desconforto e estresse são cada vez mais recorrentes. Isso porque o estresse está ligado ao desgaste resultante de um esforço psíquico fora do normal, que o indivíduo exerce para responder a determinadas situações. Ferraz, Francisco e Oliveira (2014) atribuem a esse fenômeno as mudanças ocorridas no ambiente de trabalho, especialmente, no que tange às transformações tecnológicas do mercado e seus impactos na operacionalização do trabalho, ressalvando, contudo, que nem todo estresse pode ser considerado prejudicial.

Segundo os mesmos autores, o estresse se caracteriza não como uma doença, mas como um estado dos organismos frente as demandas do meio. $O$ corpo sofre, normalmente, reações químicas que o preparam para enfrentar situações estressantes. Porém, quando essas situações são contínuas, ocorrem muitas reações e o organismo não dispõe do tempo necessário para o descanso e recuperação física e emocional. Canova e Porto (2010) já identificavam, na literatura internacional, alguns fatores que predispõem ao estresse ocupacional, como a natureza da tarefa e do papel ocupacional, as características pessoais e as variáveis de natureza situacional e pessoal, como suporte social e conflitos.

Por outro lado, esses autores afirmam que as pesquisas nacionais apresentam os fatores de predisposição como sobrecarga de trabalho, interferência família-trabalho, clima organizacional, gênero, prática de atividade física, valores pessoais, falta de autonomia, alto grau de esforço físico e mental, falta de participação na tomada de decisão, riscos de segurança, suporte social e intervenções para manipular o estresse. Marras e Veloso (2012) alertam para as consequências do estresse ocupacional, que se manifestam por meio de diversas reações, tais como: faltas, atrasos, saídas antecipadas, ausências por questões médicas provenientes do estresse, turnover, retrabalhos, acidente de trabalho, e até mesmo hostilidade entre as pessoas. Esses autores também mencionam que é difícil mensurar os custos, que o estresse ocupacional acarreta para a empresa, mas independente deste fator é obrigação da empresa zelar pela saúde física e mental de seus colaboradores.

Jex et al. (2012) ratificam afirmando que o estresse ocupacional é oneroso para as empresas, em termos financeiros, em função de atendimentos médicos, afastamentos, absenteísmo, rotatividade, redução da eficácia dos colaboradores e acidentes de trabalho. Ademais, Ferraz, Francisco e Oliveira (2014) identificaram que imposições de programas e prazos reduzidos, competição interna e variações econômicas podem resultar em exaustão mental dos indivíduos. Desse modo, com a elevação dos níveis de estresse, no ambiente de trabalho, a queda da produtividade, faltas frequentes e maior incidência de assistência médica, podem gerar um alto custo para as organizações.

Percebe-se que, com estas pesquisas, a relevância em estudar o estresse no exercício da função dos profissionais da área da 
Segurança Pública. Complementando, Selokar et al. (2011) afirmam que o estresse ocupacional em policiais pode apresentar como consequência a redução da produtividade, o absentismo, o aumento do número de relações de conflito com os demais, além de problemas físicos e emocionais e pouca satisfação com a vida. Vasconcelos (2011) explica que as condições adversas de trabalho, os riscos, as jornadas de trabalho e a pressão da sociedade em busca de eficiência levam esses profissionais a doenças ocupacionais, altos índices de estresse, entre outros distúrbios. A evolução dos sintomas desencadeia o abuso de substâncias, como o álcool, levando à violência, ao desespero e, em casos extremos, ao suicídio.

Sendo assim, faz-se necessário mensurar o estresse ocupacional, uma das escalas utilizadas é a Escala de Estresse no Trabalho (EET), elaborada e validada por Paschoal e Tamayo (2004), de fácil aplicação em diversos ambientes de trabalho e ocupações. Esta escola é composta por 23 itens, que formam um único fator (unifatorial), sendo que cada item aborda tanto um estressor (sobrecarga de trabalho, conflito entre papéis, ambiguidade de papéis, relacionamento interpessoal no trabalho, fatores de desenvolvimento na carreira e autonomia/controle no trabalho) quanto uma reação emocional a este. A percepção é vista como mediadora do impacto no ambiente de trabalho. Cada um dos 23 itens é composto por uma escala de cinco opções de resposta: 1 (discordo totalmente), 2 (discordo), 3 (concordo em parte), 4 (concordo), 5 (concordo totalmente).

Segundo Paschoal e Tamayo (2004, p. 50), "os instrumentos utilizados para avaliar o estresse ocupacional consideram ou uma escala de estressores ou uma escala de reações e, quando consideram as duas, não estabelecem um nexo entre elas". Desse modo, a EET evita fazer duas avaliações separadas, além de considerar a percepção do indivíduo, indo de encontro às críticas que abordam estressores ou reações, de forma isolada, preenchendo lacunas deixadas pelos demais instrumentos de avaliação. A EET também apresenta uma versão reduzida com 13 itens, constando os principais estressores e as reações psicológicas. Com base no exposto, definiu-se, para a presente pesquisa, utilizar a EET em sua versão completa para mensurar o estresse ocupacional em policiais militares pesquisados no Estado do Rio Grande do Sul.

Apresentadas as principais considerações sobre as temáticas, satisfação no trabalho e estresse ocupacional, no próximo item se aborda o método adotado para atingir os objetivos do presente estudo.

\section{MÉTODO}

Trata-se de uma pesquisa de natureza descritiva que, segundo Gil (2007, p. 42), tem "como objetivo primordial a descrição das características de determinada população ou fenômeno ou, então, o estabelecimento de relação entre variáveis". A pesquisa descritiva se caracteriza, também, pelas técnicas de coletas de dados, dentre elas, o questionário.
Já a abordagem da pesquisa definida é a quantitativa. Lopes et al. (2008) a classificam assim, pois permite identificar características populacionais, que podem ser quantificadas. Diehl e Tatim (2004) justificam-na pelo uso da quantificação, tanto na coleta quanto no tratamento das informações, por meio de técnicas estatísticas, envolvendo coeficiente de correlação e análise de correspondência. $\mathrm{O}$ objetivo da pesquisa quantitativa é garantir resultados e evitar distorções de análise e de interpretação, garantindo uma margem maior de segurança quanto às inferências.

O tipo de pesquisa utilizado é a survey, pois para Babbie (2001, p. 96): "permite enunciados descritivos sobre alguma população, isto é, descobrir a distribuição de certos traços e atributos. Nestes, o pesquisador não se preocupa com o porquê da distribuição existir, mas como que ela é". Para esse autor, a pesquisa survey demonstrou atender o objetivo da pesquisa, apresentando o cenário atual da Brigada Militar, no Estado do Rio Grande do Sul, no que se refere à relação entre satisfação no trabalho e estresse ocupacional.

O presente estudo foi realizado no Estado do Rio Grande do Sul, com os policiais militares, que fazem parte da Brigada Militar. A população do estudo foi composta por cerca de 33.650 (trinta e três mil, seiscentos e cinquenta) servidores militares (RIO GRANDE DO SUL, 2015). Para Malhotra (2006), população é considerada a soma de todos os elementos que compartilham algum conjunto de características comuns.

Para o cálculo da amostra do estudo se adotou a fórmula estatística para população finita, com base em Lopes et al. (2008, p. 94), segundo a equação:

$$
n=\frac{Z_{\alpha / 2}^{2} \cdot \hat{p} \cdot \hat{\mathrm{q}} \cdot \mathrm{N}}{e^{2}(N-1)+Z_{\alpha / 2}^{2} \cdot \hat{p} \cdot \hat{\mathrm{q}}}
$$

Em que:

Za/2 = valor padrão de $Z$ (distribuição normal) para um nível de confiança de $95 \%=1,96$

$\mathrm{p}^{\wedge}=$ percentual estimado $=0,5$

$q^{\wedge}=$ complemento de $\hat{\mathbf{q}}=1-\hat{p}=0,5$

$\mathrm{e}=$ erro amostral $=0,05$

$\alpha=$ nível de significância $=0,05$

Assim, considerando-se um erro amostral de $5 \%$ e um nível de $95 \%$ de confiança dos dados em uma população de 33.650 policiais militares, o tamanho da amostra é de, no mínimo, 381 indivíduos. No entanto, foi possível constituir uma amostra de 519 policiais militares, que trabalham efetivamente em 97 municípios do Estado do Rio Grande do Sul.

Para a escolha dos Policias Militares, a amostragem foi não probabilística, uma vez que a inclusão de cada policial foi de acordo com a disponibilidade no dia e horário determinado pela Brigada Militar para a aplicação. Assim, utilizou-se uma amostragem por conveniência, para a escolha dos policiais que participaram da 
pesquisa, mesmo que tenha sido calculada uma amostra mínima, utilizando um método probabilístico.

Quanto aos aspectos éticos da pesquisa, a mesma foi registrada no Gabinete de Projetos (GAP) do Centro de Ciências Sociais e Humanas (CCSH) da Universidade Federal de Santa Maria (UFSM), sob o número de projeto 036461. Realizada esta etapa, o projeto foi destinado ao Comando Geral da Brigada Militar do Estado para registro, avaliação e liberação. Posteriormente, o referido estudo foi registrado no Sistema Nacional de Ética em Pesquisa (SISNEP), sob certificado de apresentação para apreciação ética (CAAE) de nํ 31304914.4.0000.5346.

A coleta de dados foi realizada no período compreendido entre julho a outubro de 2014, no qual se utilizou um Protocolo de Pesquisa composto por 60 itens e dividido em três partes:

- Parte I: Dados pessoais e ocupacionais;

- Parte II: Escala de Estresse no Trabalho (EET) proposta por Paschoal e Tamayo (2004), composta por 23 itens

- Parte III: Escala de Satisfação no Trabalho (EST), de Siqueira (2008), constituída por 25 itens.

Após a coleta, os dados foram organizados em uma planilha eletrônica, no programa Office Excel, criando assim, um banco de dados para, posteriormente, ser analisado eletronicamente com o auxílio do programa Statistical Package for Social Sciences (SPSS) versão 21.

Primeiramente, foi feita a análise descritiva dos dados e, após, foi utilizado o indicador de consistência interna Alpha de Cronbach, que tem como propósito averiguar a confiabilidade das escalas dos questionários. Foram realizadas análises descritivas simples, a verificação do Coeficiente de Correlação de Pearson, e a Análise de Correspondência.

O objetivo do coeficiente de Pearson é encontrar a relação entre duas variáveis, isto é, um coeficiente de correlação. O r de Pearson possui características próprias, tais como: assume valores positivos (+) e negativos (-) que variam de +1 a -1 , passando por zero, logo, valores de $r$ próximos $a+1$ são indicativos de pouca dispersão, $o$ que expressa uma correlação forte e positiva, enquanto que $r$ próximo de zero indica muita dispersão e ausência de relação entre as variáveis e, por fim, $r$ próximo de -1 significa pouca dispersão e uma correlação forte e negativa (LOPES et al., 2008).

Já a análise de correspondência é uma técnica multivariada de interdependência, que facilita tanto a redução dimensional da classificação de objetos, em um conjunto de atributos, quanto o mapeamento espacial de objetos relativos a esses atributos (HAIR JR. et al., 2005).

Discorridos o percurso metodológico adotado e o modo como foram analisados os dados do presente estudo, passa-se para apresentação e análise dos resultados obtidos, a partir da aplicação da pesquisa.

\section{ANÁLISE DOS RESULTADOS}

Os resultados deste estudo são discutidos na seguinte ordem: primeiramente, a caracterização do perfil dos policiais militares pesquisados, seguido da avaliação da confiabilidade das escalas. Posteriormente, a correlação entre os níveis de satisfação no trabalho e o nível de estresse ocupacional e, finalmente, a associação entre os níveis de satisfação no trabalho e de estresse ocupacional.

\section{Caracterização do perfil dos policiais militares pesquisados}

Quanto aos dados pessoais dos 519 policiais militares, a maior concentração dos respondentes foi no gênero masculino com o total de 433 policiais $(83,43 \%)$, enquanto que o gênero feminino foi de 86 policiais (16,57\%). Cappelle e Melo (2010) mencionam que a policia militar pode ser considerada uma espécie de gueto masculino, no qual há pouco tempo as mulheres começaram a fazer parte. Além disso, a participação tem ocorrido, principalmente, em funções administrativas e de relações públicas, sem predomínio na atividade fim da polícia, que é o policiamento operacional.

Em relação às faixas de idade, o predomínio se encontra entre 31 anos ou mais, com 345 respondentes da pesquisa (66,47\%), 163 $(31,41 \%)$ têm até 30 anos, e 11 (2,12\%) policiais não responderam essa questão. Quanto ao estado civil, a maioria dos policiais 376 $(72,45 \%)$ registra estar casada, seguidos de $96(18,50 \%)$ solteiros, 46 separados $(8,86 \%)$, sendo que apenas um $(0,19 \%)$ policial não respondeu esta questão. Percebe-se que o índice está de acordo com os achados de Souza et al. (2012), que em pesquisa registraram $75,4 \%$ de policiais casados.

Quanto ao fato de possuir filhos, 351 (67,63\%) policiais responderam possuir, enquanto $168(32,37 \%)$ não possuem. Dos policiais que possuem, a maioria $149(42,45 \%)$ tem apenas um filho, seguidos por 137 (39,03\%) com dois filhos, 46 (13,11\%) com três filhos e 19 (5,41\%) com quatro filhos ou mais.

A respeito da escolaridade, grande parte dos policiais 307 (59,15\%) possui o Ensino Médio, seguido de 118 (22,74\%) com graduação incompleta, 68 (13,10\%) com graduação completa, 24 $(4,62 \%)$ com pós-graduação, e dois $(0,39 \%)$ policiais não responderam esta pergunta. Os achados de Costa et al. (2007) na pesquisa com policiais militares da cidade de Natal/RN também identificaram que a maior parte $(77,3 \%)$ dos pesquisados possuem o Ensino Médio completo.

A respeito dos dados ocupacionais dos policiais pesquisados, quanto ao tempo de atuação na Instituição, a maioria está a 21 a 30 anos, registrando 166 policiais (31,98\%), seguido por 5 a 10 anos com 162 policiais $(31,27 \%), 85(16,41 \%)$ de 11 a 20 anos, 70 $(13,51 \%)$ de 1 a 4 anos e $35(6,76 \%)$ a mais de 30 anos, e um $(0,19 \%)$ policial preferiu não responder a pergunta. É possível identificar que, na amostra estudada, prevalecem policiais com muitos anos de profissão (21 a 30 anos), seguido por um público com tempo intermediário (5 a 10 anos). Quanto ao posto que os policiais pesquisados ocupam, a maioria 305 (58,76\%) são 
soldados, $198(38,15 \%)$ sargentos, 8 (1,54\%) tenentes, 4 (0,77\%) capitães, $2(0,39 \%)$ subtenentes, e $2(0,39 \%)$ policiais não responderam essa questão.

Em relação à atividade que desempenham, houve concentração de 221 policiais (42,58\%) em atividades externas, $211(40,66 \%)$ em ambas (interna e externa) e 84 (16,18\%) apenas atividades internas, e três $(0,58 \%)$ policiais preferiram não responder. Quanto à renda dos policiais pesquisados, a concentração se encontra entre 1 a 3 salários mínimos com 272 policiais (52,41\%), seguido por $218(42,00 \%)$ registrando de 4 a 6 salários mínimos, por fim, 22 policiais $(4,24 \%)$ recebem 7 salários mínimos ou mais, e sete $(1,35 \%)$ policiais optaram por não responder essa pergunta.

O grau de responsabilidade pela manutenção financeira da família foi outro questionamento abordado. Grande parte dos respondentes afirmou que divide, igualmente, as responsabilidades com outra pessoa, registrando 184 (35,45\%). Seguidos pelos que são os principais responsáveis, mas recebem ajuda de outra pessoa, respondido por 160 policiais (30,83\%), e 159 policiais $(30,64 \%)$ informaram ser o único responsável. Por fim, 10 policiais $(1,93 \%)$ contribuem apenas com uma pequena parte e 5 policias $(0,96 \%)$ não tem nenhuma responsabilidade financeira junto a família. Apenas um $(0,19 \%)$ policial preferiu não responder.
Assim, resumidamente se pode afirmar que a amostra do presente estudo é, predominantemente, do gênero masculino, com idade entre 31 anos ou mais, casados, com um filho e Ensino Médio completo. Quanto aos dados ocupacionais, a amostra é predominantemente constituída por policiais militares, que possuem de 21 a 30 anos (31,98\%) de atuação na Brigada Militar, soldados $(58,76 \%)$, que exercem atividades externas $(42,58 \%)$, com renda entre 1 a 3 salários mínimos (52,41\%), e dividem igualmente a responsabilidade pela manutenção financeira da família com outra pessoa $(35,45 \%)$.

\section{Avaliação da Confiabilidade das Escalas}

No presente estudo, a confiabilidade das escalas foi avaliada utilizando-se o coeficiente alpha de cronbach. Segundo Hair Jr. et al. (2005), um nível satisfatório de confiabilidade quer dizer que as respostas dos pesquisados estão apresentando coerência, no respectivo instrumento, composto por escalas. Para esse autor, uma variação do alpha de cronbach entre 0,7 a 0,8 é considerada uma associação boa, enquanto que o valor acima de 0,9 é considerado excelente, pois quanto mais próximo de 1 o coeficiente, maior a confiabilidade do instrumento.

Tabela 1 - Confiabilidade das escalas

\begin{tabular}{|c|c|c|}
\hline \multirow{2}{*}{ Modelos teóricos } & \multicolumn{2}{|c|}{ Alpha de Cronbach } \\
\hline & Original & Obtido na pesquisa \\
\hline Escala de Estresse no Trabalho (EET) de Paschoal e Tamayo (2004) & 0,91 & 0,932 \\
\hline Escala de Satisfação no Trabalho (EST) de Siqueira (2008) & - & 0,940 \\
\hline Satisfação com os colegas & 0,86 & 0,826 \\
\hline Satisfação com o salário & 0,92 & 0,934 \\
\hline Satisfação com a chefia & 0,90 & 0,899 \\
\hline Satisfação com as promoções & 0,87 & 0,907 \\
\hline Satisfação com a natureza do trabalho & 0,82 & 0.793 \\
\hline
\end{tabular}

$\mathrm{Na}$ Tabela 1 se verifica que os alphas de cronbach obtidos, nesse estudo, para a Escala de Estresse no Trabalho (EET) de Paschoal e Tamayo de $2004(\alpha=0,932)$ e para a Escala de Satisfação no Trabalho (EST) de Siqueira de 2008 ( $\alpha=0,940)$, confirmaram um nível satisfatório de consistência interna e confiabilidade dos dados, segundo Hair Jr. et al. (2005). Confirmaram-se, da mesma forma, as dimensões de satisfação no trabalho de Siqueira (2008): satisfação com os colegas $(\alpha=0,826)$, satisfação com o salário $(\alpha=0,934)$, satisfação com a chefia $(\alpha=0,899)$, satisfação com a natureza do trabalho $(\alpha=0,793)$ e satisfação com as promoções ( $\alpha=0,907)$.

Lelis (2013), ao estudar o nível de estresse e o grau de satisfação relacionado ao trabalho de gestores, na área comercial, obteve índices de consistência e confiabilidade das escalas consideradas muito boas. Na Escala de Estresse no Trabalho (EET) de Paschoal e Tamayo, de 2004, obteve o alpha de cronbach de 0,93 e para a Escala de Satisfação no Trabalho (EST) de Siqueira, de 2008, registrou o índice de 0,906 do coeficiente.
Os indicadores obtidos nas análises deste estudo e apresentados na Tabela 1 confirmaram a validação da confiabilidade da Escala de Estresse no Trabalho (EET) de Paschoal e Tamayo, de 2004, e da Escala de Satisfação no Trabalho (EST) de Siqueira, de 2008. Na Tabela 1 se verifica que os alphas de cronbach das duas escalas, assim como por dimensão da escala de satisfação, registram valores entre 0,793 e 0,940.

\section{Correlação entre os níveis de satisfação no trabalho e o nível de estresse ocupacional}

Buscando verificar a existência de correlação entre a satisfação no trabalho, suas dimensões, e o estresse ocupacional, as mesmas foram submetidas a um tratamento estatístico com o teste de correlação paramétrico de Pearson, conforme apresentado na Tabela 2. 
Tabela 2 - Matriz de correlação e as significâncias de estresse ocupacional, satisfação no trabalho e suas dimensões

\begin{tabular}{|c|c|c|c|c|c|c|c|c|}
\hline & \multirow{2}{*}{ Matriz } & \multicolumn{7}{|c|}{ Significância } \\
\hline & & Estresse & Sat_Col & Sat_Sal & Sat_Chef & Sat_Natur & Sat_Prom & Satisfaç \\
\hline \multirow{7}{*}{ : } & Estresse & 1.00000 & $\mathrm{p}=0,00$ & $\mathrm{p}=0,00$ & $\mathrm{p}=0,00$ & $\mathrm{p}=0,00$ & $\mathrm{p}=0,00$ & $\mathrm{p}=0,00$ \\
\hline & Sat_Col & $-0,3135$ & 1.00000 & $p=0,00$ & $p=0,00$ & $\mathrm{p}=0,00$ & $p=0,00$ & $p=0,00$ \\
\hline & Sat_Sal & $-0,3701$ & 0,2288 & 1.00000 & $p=0,00$ & $p=0,00$ & $p=0,00$ & $p=0,00$ \\
\hline & Sat_Chef & $-0,5736$ & 0,4852 & 0,4155 & 1.00000 & $p=0,00$ & $p=0,00$ & $p=0,00$ \\
\hline & Sat_Natur & $-0,4827$ & 0,5749 & 0,5210 & 0,6175 & 1.00000 & $p=0,00$ & $p=0,00$ \\
\hline & Sat_Prom & $-0,4736$ & 0,2697 & 0,7272 & 0,4725 & 0,5520 & 1.00000 & $\mathrm{p}=0,00$ \\
\hline & Satisfação & $-0,5766$ & 0,6119 & 0,7955 & 0,7665 & 0,8247 & 0,8249 & 1.00000 \\
\hline
\end{tabular}

Correlações significativas $(p<0,05)$; altamente significativas $(p<0,001)$; $n=519$.

Constata-se na Tabela 2, que a maior parte das correlações entre os construtos foram associações positivas, o que indica haver relação direta entre estas. Quanto ao estresse ocupacional este apresenta correlação negativa e estatisticamente significante com a satisfação no trabalho nas suas cinco dimensões, classificando tais relações como moderadas e negativas; o que demonstra que quanto maior o estresse ocupacional, menor a satisfação no trabalho e vice-versa.

As dimensões satisfação com a chefia $(p=-0,5736)$ e satisfação com a natureza do trabalho $(p=-0,4827)$ são as que apresentam maior correlação negativa com o estresse ocupacional. Tamayo, Lima e Silva (2002, p. 10) mencionam que o suporte social, que pode ser proporcionado pela chefia "evita ou reduz as reações de estresse porque ele oferece ao empregado um sentido humano da sua situação laboral e um reconhecimento do seu valor como pessoa e como profissional". Além disso, os autores ao pesquisarem empregados de uma empresa pública do setor elétrico, identificaram que o estilo de liderança gerencial é determinante para o estresse ocupacional. Assim, parece correto afirmar que quanto maior a inadequação no estilo de liderança em determinado contexto organizacional, maior será o estresse.

Também foi possível identificar a correlação e, consequentemente, contribuição, das cinco dimensões para a formação da satisfação no trabalho (geral). As maiores contribuições foram registradas nas dimensões satisfação com as promoções $(p=0,8249)$, satisfação com a natureza do trabalho ( $p$ $=0,8247)$, satisfação com o salário $(p=0,7955)$ e satisfação com a chefia ( $p=0,7665)$. Estas apresentaram uma correlação forte e positiva, por sua vez, a dimensão satisfação com os colegas ( $p=$ $0,6119)$ também contribuindo, mas de forma moderada e positiva.

Lelis (2013) identificou achados semelhantes, em que o nível de estresse é inversamente proporcional ao nível de satisfação no trabalho, isto é, quanto maior o nível de estresse, menor o nível de satisfação no trabalho e quanto menor o nível de estresse, maior o nível de satisfação no trabalho.
Figura 1 - Relação entre satisfação no trabalho e estresse ocupacional

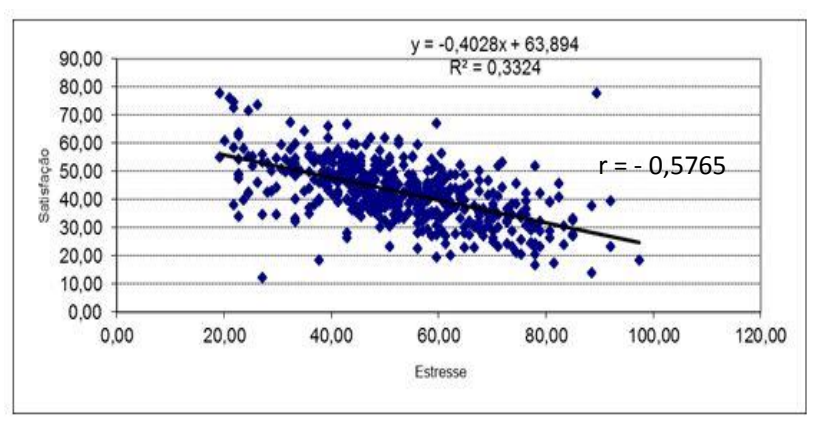

Ao analisar o gráfico de dispersão (Figura 1), confirma-se que quanto maior a satisfação no trabalho, menor o estresse ocupacional, e vice-versa. A curva decrescente ocorre em função do coeficiente de regressão, que se apresenta com o valor negativo (Satisfação $=-0,4028$ estresse $+63,894$ ). Tais resultados vão ao encontro dos achados de Johnson (2012) que identificou que as fontes de estresse e os conflitos contribuem, de forma significativa, para a baixa satisfação no trabalho. O que vem a ressaltar a importância da valorização e ampliação dos serviços de aconselhamento para policiais, além de treinamento em técnicas de gestão de estresse.

\section{Associação entre os níveis de satisfação no trabalho e os níveis de estresse ocupacional}

A associação entre os níveis de satisfação no trabalho e os níveis de estresse dos policiais pesquisados foi realizada por meio da técnica de análise de correspondência. Segundo Hair Jr. et al. (2005), esta técnica utiliza uma tabela de contingência, que é a tabulação cruzada de duas variáveis categóricas, a qual permite visualizar semelhanças e diferenças entre as variáveis.

A análise de correspondência busca representar as frequências relativas (percentuais) em gráficos bidimensionais, por meio das medidas de distância entre as categorias. A interpretação de resultados, em análise de correspondência, resulta no agrupamento de categorias (variáveis pesquisadas) na tabela de contingência, assim como a análise de componentes principais envolve 0 agrupamento das variáveis independentes. 
Segundo Malhotra (2006), os resultados são interpretados em termos de proximidade entre as linhas e as colunas. Por meio da técnica multivariada de interdependência (análise de correspondência) elabora-se um mapa espacial das médias, em relação ao grau de concordância relativa às respostas do protocolo de pesquisa, conforme Figura 2.

Figura 2 - Análise de correspondência referente aos níveis de satisfação no trabalho e aos níveis de estresse ocupacional

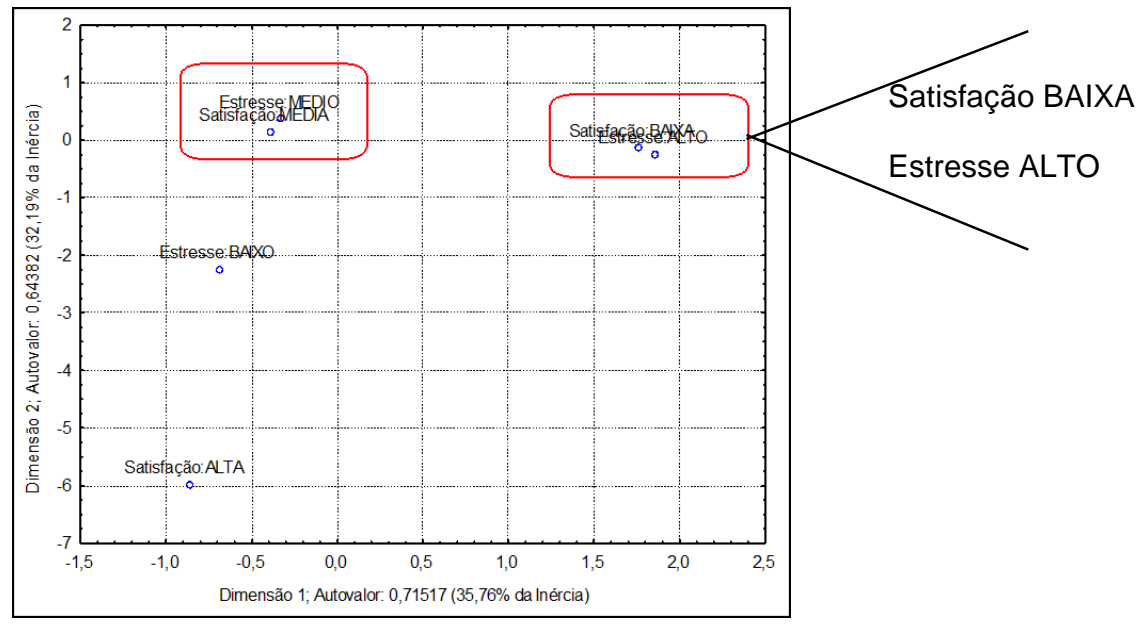

Ao relacionar os níveis de satisfação no trabalho (alta, média e baixa) e os níveis de estresse ocupacional (alto, médio e baixo), observa-se na Figura 2, que houve associação entre a satisfação baixa $(18,69 \%)$ e o estresse alto $(16,99 \%)$, pois estes estão próximos no plano cartesiano. E da mesma forma, houve associação entre satisfação média $(79,38 \%)$ e estresse médio (72,39\%). Nos achados de Martinez (2002), a satisfação no trabalho aparece, significativamente, associada à saúde do trabalhador, sendo que níveis mais elevados de satisfação com aspectos psicossociais do trabalho estavam relacionados com uma melhor condição de saúde mental e de capacidade para o trabalho entre os pesquisados.

Em contrapartida, não houve associação entre a satisfação alta $(1,93 \%)$ e o estresse baixo (10,62\%). É provável que tenha ocorrido, em virtude do baixo índice de policiais pesquisados com satisfação alta e com estresse baixo. Desta forma, parece apropriado afirmar que policiais militares, com baixa satisfação no trabalho, apresentam alto nível de estresse ocupacional e os policiais militares, com média satisfação no trabalho, um médio estresse ocupacional. Percebe-se assim, a necessidade de intervenções, que promovam a satisfação dos trabalhadores e minimizem o estresse causado pela atividade laboral. Martinez e Paraguay (2003, p. 73) alertam "sobre ações que promovam satisfação no trabalho e saúde dos trabalhadores, sugere-se projetar e avaliar mudanças na concepção e organização do trabalho e que sejam direcionadas para os aspectos psicossociais do trabalho".

Essas autoras sugerem, ainda, que as mudanças na concepção e na organização do trabalho devem atender as necessidades, expectativas e desejos dos trabalhadores envolvidos, além de compatíveis com as características e exigências das tarefas. Quando não houver a possibilidade de atendê-las é recomendado apresentar os motivos que levaram a tal, pois caso contrário, poderá ser caracterizado como aumento do volume de trabalho, das exigências, das responsabilidades, gerando conflitos e fontes de insatisfação e de riscos com a saúde.

Complementando, Robbins et al. (2010) abordam que uma das consequências psicológicas do estresse é a insatisfação no trabalho. Quanto menor o controle do indivíduo sobre o ritmo de trabalho, maiores são o estresse e a insatisfação. Em se tratando de sintomas comportamentais, as consequências incluem mudanças na produtividade, rotatividade, absenteísmo, mudança nos hábitos alimentares, aumento no consumo de álcool e distúrbios do sono.

Finalizando, no próximo item serão apresentadas as considerações finais acerca da presente pesquisa, assim como as limitações e sugestões de próximos estudos.

\section{CONSIDERAÇÕES FINAIS}

O presente estudo buscou responder o seguinte objetivo geral: "analisar as relações entre satisfação no trabalho e estresse ocupacional na perspectiva dos policiais militares do Estado do Rio Grande do Suf'. A fim de respondê-lo se fez uso de duas técnicas estatísticas: a correlação de Pearson e a análise de correspondência. Com a primeira técnica, a correlação de Pearson, identificou-se que o estresse ocupacional apresenta correlação negativa e estatisticamente significante $(p<0,05)$ com a satisfação no trabalho e suas cinco dimensões, comprovando que quanto maior o estresse ocupacional, menor a satisfação no trabalho, e vice-versa. Também foi possível verificar a correlação e, consequentemente, contribuição, das cinco dimensões para a formação da satisfação no trabalho. Johnson (2012), em seus achados, afirma que as fontes de estresse e os conflitos 
contribuem, de forma significativa, para a baixa satisfação no trabalho.

A técnica estatística análise de correspondência foi utilizada para responder ao objetivo, que teve como foco: "associar o nível de satisfação no trabalho com o nível de estresse ocupacional dos policiais militares pesquisados". Ao analisar tais dados se constatou que houve associação entre a baixa satisfação no trabalho e o alto estresse ocupacional. E da mesma forma, houve associação entre média satisfação no trabalho e nível médio de estresse ocupacional. Em contrapartida, não houve associação entre o alto nível de satisfação e o nível baixo de estresse ocupacional. Provavelmente, em virtude do baixo índice de policiais pesquisados, que apresentaram alta satisfação no trabalho e baixo estresse ocupacional.

Desta forma, identificou-se que policiais militares, com baixa satisfação no trabalho, apresentam alto nível de estresse ocupacional. E policiais militares com média satisfação no trabalho apresentam médio nível de estresse ocupacional. Percebe-se, assim, a necessidade de intervenções, que promovam a satisfação dos trabalhadores e minimizem o estresse causado a partir de estressores da atividade laboral. Corroborando com tais achados, Lelis (2013) também identificou, em sua pesquisa, que o nível de estresse é proporcionalmente inverso ao nível de satisfação no trabalho, isto é, quanto maior o nível de estresse, menor o nível de satisfação no trabalho e quanto menor o nível de estresse, maior o nível de satisfação no trabalho.

Por fim, aponta-se como uma das limitações desse estudo a dificuldade em comparar os achados obtidos, no presente estudo, com outras pesquisas sobre tais temáticas e, especificamente, com policiais militares. Além desta limitação, o fato da coleta dos dados ter ocorrido em apenas um Estado do Brasil, também é limitador, de modo que a generalização dos resultados é restrita à realidade do Estado do Rio Grande do Sul. Sugere-se, para estudos futuros, replicar esta pesquisa com uma amostra nas diversas regiões brasileiras, e até mesmo em outros países, a fim de realizar análises comparativas.

O tipo de abordagem de pesquisa também é um fato limitador, visto que se fez uso apenas da abordagem quantitativa. Sugere-se, para estudos futuros adotar a abordagem qualitativa aliada com a abordagem quantitativa, podendo realizar entrevistas com uma amostra do contingente militar, a fim de identificar possíveis peculiaridades, que não foram percebidas no presente estudo. Sugere-se, também, realizar esta mesma pesquisa sob um viés longitudinal, pois este tipo de abordagem possibilita acompanhar o desenvolvimento e a mudança nos níveis de satisfação no trabalho e nos níveis de estresse ocupacional dos sujeitos de pesquisa.

\section{REFERÊNCIAS}

Babbie, E. (2001) Métodos de Pequisas de Survey. Belo Horizonte: UFMG.

Brasil. (2001). Ministério da Saúde do Brasil. Doenças relacionadas ao trabalho. Manual de procedimentos para os serviços de saúde. Organização Pan-Americana da Saúde/Brasil. Série A. Normas e manuais técnicos, n. 114, Brasília: DF.

Caldas, C. B.; Somensari, P.; Costa, S. N.; Siqueira, M. M. M.; Claro, J. A. C. S. (2013). Satisfação e engajamento no trabalho: docentes temáticos e auxiliares da EAD de universidade privada brasileira. Gerais: Revista Interinstitucional de Psicologia, v. 6, n. 2, p. 225-237.

Canova, K. R.; Porto, J. B. (2010, set./out.) O Impacto dos Valores Organizacionais no Estresse Ocupacional: um estudo com professores de ensino médio. RAM - Revista de Administração Mackenzie, v. 11, n. 5.

Cappelle, M. C. A.; Melo, M. C. O. L. (2010, mai./jun.). Mulheres policiais, relações de poder e de gênero na polícia militar de Minas Gerais. RAM, Rev. Adm. Mackenzie, v. 11, n. 3, Edição Especial.

Costa, M.; Accioly JR, H.; Oliveira, J.; Maia, E. (2007). Estresse: diagnóstico dos policiais militares em uma cidade brasileira. Revista Panamericana de Salud Pública, v. 21, n. 4, p. 217-22.

$\begin{array}{llll}\text { Brigada Militar. Institucional. Disponível em: < } & \end{array}$ em: 30 jan. 2015

Diehl, A. A.; Tatim, D. C. (2004). Pesquisa em Ciências Sociais Aplicadas: métodos e técnicas. São Paulo: Prentice Hall.

Ferreira, M. L. C. B.; Siqueira, M. M. M. (2005). Antecedentes de Intenção de Rotatividade: estudo de um modelo psicossocial. Organizações em contexto, ano 1, n. 2, p. 47-67.

Figueiredo, J. M. (2012). Estudo Sobre a Satisfação no Trabalho dos Profissionais de Informação de Uma IFES. 2012. 175 f. Dissertação (Mestrado em Sistemas de Gestão) - Universidade Federal Fluminense, Niterói.

Ferraz, F. C; Francisco, F. R.; Oliveira, C. S. Estresse no ambiente de trabalho. Archives of Health Investigation, v. 3, n. 5, p. 1-8, 2014.

Gil, A. C. (2007). Como elaborar projetos de pesquisa. São Paulo: Atlas.

Gondim, S. M. G.; Siqueira, M. M. M. (2004). Emoções e afetos no trabalho. In: Zanelli, J.C.; Borges-Andrade, J. E.; Bastos, A.V. B. (Orgs.). Psicologia, Organizações e Trabalho no Brasil. Porto Alegre: Artmed.

Hair Jr., J. F.; Babin, B.; Money, A. H.; Samouel, P. (2005). Fundamentos de métodos de pesquisa em administração. Porto Alegre: Bookman.

Hurrell Jr., J. J.; Sauter, S. L. (2011). Stress Ocupacional: causas, consequências, prevenção e intervenção. In: Rossi, A. M.; Perrewé, P. L.; Meurs, J. A (Org.). Stress e Qualidade de Vida no Trabalho: stress social enfrentamento e prevenção. São Paulo: Atlas.

Jex, S. M.; Cunningham, C. J. L.; Rosa, G. D. L.; Broadfoot, A. (2012). Stress e Eficácia dos Funcionários. In: Rossi, A. M.; Perrewé, P. L.; Sauter, S. L. (Org.). Stress e Qualidade de Vida no Trabalho: perspectivas atuais da saúde ocupacional. São Paulo: Atlas.

Johnson, R. R. (2012). Police Officer Job Satisfaction: a multidimensional analysis. Policy Quarterly, v. 15, n. 2, p. 157-176.

Lelis, J. W. F. (2013). Estresse e satisfação no trabalho de profissionais que exercem a função de gestores na área comercial. 2013. $117 \mathrm{f}$. Dissertação (Mestrado em Administração) - Pontifícia Universidade Católica de São Paulo, São Paulo.

Lopes, L. F. D.; Muller, I.; Souza, A. M. Ansuj, A. P.; Moraes, D. A. O.; Moreira Jr.; F. J.; Pulgati, F. H.; Strazzabosco, F. (2008). Estatística geral. Caderno didático. 3. ed. Santa Maria: UFSM.

Malhotra, N. F. N. (2006). Pesquisa de marketing: uma orientação aplicada. 4. ed. Porto Alegre: Bookman.

Marras, J. P.; Veloso, H. M. (2012). Estresse Ocupacional. Rio de Janeiro: Elsevier.

Martinez, M. C.; Paraguay, A. I. B. B. (2003). Satisfação e saúde no trabalho: aspectos conceituais e metodológicos. Cadernos de Psicologia Social do Trabalho, v. 6, p. 59-78.

Martinez, M. C. (2002). As relações entre a satisfação com aspectos psicossociais no trabalho e a saúde do trabalhador. Dissertação (Mestrado em Saúde Pública) - Universidade de São Paulo, São Paulo.

Martins, M. C. F.; Santos, G. E. (2006). Adaptação e validação da Escala de Satisfação no Trabalho. Psico-USF, v. 11, n. 2, p. 195-205.

Neves, V. F. (2012). Impacto da satisfação no trabalho e da percepção de suporte organizacional sobre a Síndrome de Burnout em trabalhadores de enfermagem de um Hospital Universitário. 2012. 135 f. Dissertação (Mestrado em Psicologia Aplicada) - Universidade Federal de Uberlândia, Uberlândia.

Oliveira, A. L. M.; Bardagi, M. P. (2010). Estresse e comprometimento com a carreira em policiais militares. Boletim de Psicologia, v. LIX, n. 131

Oliveira, I. (2012). A relação entre as práticas de gestão de pessoas, satisfação no trabalho e desempenho organizacional nos hotéis turísticos da zona central de Manaus. 2012. 172 f. Dissertação (Mestrado em Turismo e Hotelaria) - Universidade do Vale do Itajaí, Balneário Camboriú.

Paschoal, T.; Tamayo, A. (2004). Validação da escala de estresse no trabalho. Estudos de psicologia, v. 9, n. 1, p. 45-52. 
Rio Grande do Sul. (1997). Lei n. 10.999, de 18 de agosto de 1997. Fixa o efetivo da Brigada Militar do Estado e dá outras providências. Disponível em: <http://www.al.rs.gov.br/FileRepository/repLegisComp/10.999.pdf>. Acesso em: 20 jan. 2015.

Robbins, S. P.; Judge, T. A.; Sobral, F.(2010). Comportamento Organizacional: teoria e prática no contexto brasileiro. 14 ed. São Paulo: Pearson Prentice Hall.

Rothmann, I.; Cooper, C. (2009). Fundamentos de Psicologia Organizacional e do Trabalho. Rio de Janeiro: Elsevier.

Selokar, D.; Nimbarte, S.; Ahana, S.; Gaidhane, A.; Wagh, V. (2011). Occupational stress among police personnel of Wardha City, India. Australasian Medical Journal AMJ, v. 4, n. 3, p. 114-117.

Siqueira, M. M. M. (2008). Satisfação no trabalho. In: SIQUEIRA, M.M.M. (Org.) Medidas do Comportamento Organizacional: ferramentas de diagnóstico e de gestão. Porto Alegre: Artmed.

Siqueira, M. M. M.; Gomide Júnior, S. (2004). Vínculos do indivíduo com o trabalho e com a organização. In: Zanelli, J. C.; Borges-Andrade, J. E; Bastos, A.V.B. (Orgs.). Psicologia, Organizações e Trabalho no Brasil. Porto Alegre: Artmed, p. 300-328.

Souza, E. R.; Minayo, M. C. S. (2005). Policial, risco como profissão: morbimortalidade vinculada ao trabalho. Ciência \& Saúde Coletiva, v. 10, n. 4, p. 917-928.
Souza, E. R; Minayo, M. C. S.; Silva, J. G.; Pires, T. O. (2012, jul.). Fatores associados ao sofrimento psíquico de policiais militares da cidade do Rio de Janeiro, Brasil. Cad. Saúde Pública, Rio de Janeiro, v. 28, n. 7, p.1297-1311.

Spector, E. P. (2012). Psicologia nas Organizações. 4. ed. São Paulo: Saraiva.

Tamayo, A.; Lima, D.; Silva, A.V. (2002). Impacto do clima organizacional sobre o estresse no trabalho. In: XXVI ENCONTRO NACIONAL DA ANPAD, 2002, Salvador. Anais... Salvador. Disponível em: 2002, Salvador. Anais...
<http://www.anpad.org.br/diversos/trabalhos/EnANPAD/enanpad_2002/COR /2002_COR1624.pdf>. Acesso em: 30 jan. 2015.

Valle, A. R. (2007). Monitoramento da Satisfação no Trabalho em uma Empresa Financeira. 2007. 195 f. Tese (Doutorado em Psicologia) Universidade de Brasília, Brasília.

Vasconcelos, T. S. (2011). Programas de Gerenciamento do Estresse e Qualidade de Vida no Trabalho na Área de Segurança Pública. In: Rossi, A. M.; Perrewé, P. L.; Meurs, J. A (Org.). Stress e Qualidade de Vida no Trabalho: stress social - enfrentamento e prevenção. São Paulo: Atlas.

Xavier, J. W. O.; Rios, O. L.; França-Botelho, A. C. (2013). Qualidade de Vida no Trabalho, o Desafio de Vencer a Síndrome de Burnout e suas Consequências. Revista Saúde e Pesquisa, Unicesumar. v.6, n. 1, p. 117 121, jan./abr. 